\title{
Reduced Carbon and Energy Footprint in Highway Operations: The Highway Energy Assessment (HERA) Methodology
}

\author{
Natalia Sobrino • Andres Monzon • Sara Hernandez
}

\begin{abstract}
Global demand for mobility is increasing and the environmental impact of transport has become an important issue in transportation network planning and decisionmaking, as well as in the operational management phase. Suitable methods are required to assess emissions and fuel consumption reduction strategies that seek to improve energy efficiency and furthering decarbonization. This study describes the development and application of an improved modeling framework - the HERA (Highway EneRgy Assessment) methodology - that enables to assess the energy and carbon footprint of different highways and traffic flow scenarios and their comparison. HERA incorporates an average speed consumption model adjusted with a correction factor which takes into account the road gradient. It provides a more comprehensive method for estimating the footprint of particular highway segments under specific traffic conditions. It includes the application of the methodology to the Spanish highway network to validate it. Finally, a case study shows the benefits from using this methodology and how to integrate the objective of carbon footprint reductions into highway design, operation and scenario comparison.
\end{abstract}

Keywords Carbon footprint assessment · Highway operation · Consumption model

\section{Introduction}

Transport is key in fostering economic development and enhancing quality of life (Valackiene et al. 2006; Banister 2012). However, traffic and transportation systems 
also involve some negative externalities, such as energy consumption and environmental impacts. Global $\mathrm{CO}_{2}$ emissions from transport represented $22.5 \%$ of fatal $\mathrm{CO}_{2}$ emissions in 2008 in developed countries and this proportion has increased by $44 \%$ from 1990 to 2008 (OECD 2010). Transport has shown the most rapid energy consumption growth of any sector. Its share in final energy consumption is increasing worldwide, reaching $33 \%$ overall in the European Union (368 Mtoe in 2009). Road transportation in Europe is the most important consumer within the transport sector, accounting for $81 \%$ of the total EU transport consumption (Lapillonne et al. 2012). In the case of Spain, transport is the second largest and the fastest-growing source of greenhouse gas (GHG) emissions. Furthermore, the rapid growth in demand for roadbased travel has made the Spanish road transport sector responsible for $65 \%$ of total transport emissions, with GHG emissions increasing by $69 \%$ between 1990 and 2010 (European Commission 2010).

Since the Kyoto Protocol (UNFCC 1998), transport policies have been oriented toward achieving more sustainable mobility patterns. In general, these involve a set of coordinated actions aimed at the improvement of energy efficiency and the reduction of environmental impacts which focus on interurban and urban scale. On an urban scale, Sobrino and Monzon (2013) concluded that modal shift in cities may form part of the process of stabilizing the footprint of Spanish urban mobility. In the same line, Kitthamkesorn et al. (2013) developed a model which has the potential to enhance the behavioral modeling of travelers' mode shift and to evaluate the effectiveness of sustainable policies. Concerning urban freight mobility, better routing may establish efficient and environmentally friendly delivery systems (Ando and Taniguchi 2006). On a more general scale, Lopez et al. (2012) showed by means of a scenario-based assessment methodology that demand regulation measures have proven to be effective in integrated energy and transport policies. Namely, Li et al. (2013) proposed a model to optimize cordon toll pricing schemes while reduce environmental effects. Meanwhile Mendiluce and Schipper (2011) pointed out that focusing on reducing activity would be the most beneficial strategy for achieving the overall goal of GHG reduction in the Spanish transportation sector. However, if these goals are to be achieved, a variety of strategies must be considered and integrated. In order to assess the different strategies implemented in the transport sector, transportation authorities and operators need suitable methods and decision-making tools to encourage planning oriented toward reducing energy consumption and $\mathrm{CO}_{2}$ emissions (Monzon et al. 2012).

This study describes the development and application of a modeling framework the HERA (Highway EneRgy Assessment) methodology - with which to assess the carbon and energy footprint of traffic flows both at a micro (specific stretches of a highway) and macro level (highway network). The main advantage of this modeling framework is that it can be adapted to any highway network in any location. The general methodology has been customized to the traffic conditions of the Spanish highway network and applied to a specific case study.

The paper is structured as follows. First, there is a review of the incorporation of the carbon footprint into the environmental assessment of road networks and HERA contributions with respect to other existing assessment methodologies (Section 2). Section 3 describes the basis of the HERA methodology and provides a summary of its approach and architecture. In Section 4, the structure and the main assumptions of the model are described, together with the influential parameters and model 
calibrations. Section 5 presents the adaptation of HERA to the Spanish highway network and its validation through a comparison of the model's results with on-board measurements. After that, the results of a case study are presented (Section 6). Finally, a summary of the paper with its main points and contributions is given.

\section{Assessment of Road Energy and Carbon Footprint: HERA Contributions}

Wackernagel and Rees (1996) proposed the concept of the ecological footprint as a standard methodology for evaluating the direct environmental impacts of a human being during his or her lifetime. In transport, the carbon footprint of a road transport network is defined as the total amount of $\mathrm{CO}_{2}$ and other GHGs (expressed in tonnes $\mathrm{CO}_{2}$ equivalent) emitted over the full life-cycle (design, construction, operational, maintenance, and deconstruction phases) of the road.

In recent decades, a variety of definitions and procedures for the calculation of carbon footprints have been employed (Pandey et al. 2011). Chi and Stone (2005) pointed out that "the principal advantage of the footprint measure in the environmental impact analyses is that it adopts a physical variable as a common metric for comparing alternative options or models." Additionally, carbon footprint data helps in the management and evaluation of emissions mitigation measures and should be included as an indicator of sustainable development (Pandey et al. 2011).

The energy footprint is a measure of the total energy required by traffic during the operational phase of a road (expressed in MJ). Lenzen (1999) highlighted pointed out that three quarters of the energy consumed and GHG emissions produced during the life-cycle of a road are due to vehicle fuel consumption; the remaining quarter corresponds to the construction and maintenance of vehicles and infrastructure. Therefore, the operational stage is considered the most important phase of the road life-cycle, and efficient management policies could achieve significant energy and GHG emissions reductions.

Different models are used worldwide for the estimation of road traffic emissions and energy consumption. Some of them are widely used as COPERT - COmputer Programme to calculate Emissions from Road Transport - (Gkatzoflias et al. 2007), MOBILE (U.S. EPA 2002) and its recently version MOVES -Motor Vehicles Emission Simulator- (U.S.EPA, 2009), ARTEMIS -Assessment and Reliability of Transport Emission Models and Inventory Systems - (Andre 2004), or VERSIT+(Smit et al. 2007). COPERT and MOBILE use their own databases to obtain the emission factors as a function of the average cycle speed. The first one is mostly used in Europe and the second in US. ARTEMIS and VERSIT + obtain the emission factors as function of the aggregated kinematic parameters of the driving cycle (speed distribution, acceleration, etc.), drawing the information from proper databases of emissions measurements. There are other types of micro-scale models for measuring local emissions which are classified according to the instantaneous kinematic parameters (emission maps with speed and acceleration).

All these energy consumption and emission models provide tools to evaluate measures, strategies, and scenarios; they also help to integrate energy and carbon footprint management into decision-making processes (Affum et al. 2003; Szeto et al. $2013 \mathrm{a}, \mathrm{b})$. This theoretical framework has been put into practice through different 
assessment approaches to evaluate climate change impacts of road traffic. Table 1 summarizes several of these approaches and classifies them according to the emission model they use, their spatial scale, their data input requirements, the outputs dimension and their main applications. There also exist approaches which link traffic models with vehicle emissions or noise models (Szeto et al. 2013a, b).

In relation to the input requirements, the assessment methodologies could be classified according to two approaches: top-down or bottom-up. Top-down approaches are based on historical relationships between macro level variables. On the other hand, bottom-up approaches are built up from detailed data (i.e. vehicle stock, distance travelled by different vehicle categories, etc.). With regard to the spatial scale, some are designed to be applied at country level (macro), while other are applied at urban scale (micro); in both cases, their main applications are emission inventories.

The proposed HERA methodology has some new contributions:

a- Regarding to the scale, HERA is designed for specific highways sections, following a bottom-up scheme. It could be customized for each type of alignment and traffic flow situation. Therefore it could be applied to any situation, in any specific country or area, providing the necessary inputs.

b- Regarding the emissions model, HERA uses an average speed consumption model -based on the COPERT emission factors- but adjusted with a correction factor to incorporate the gradient effect on light vehicles of each road section, which is something new.

c- HERA produces richer outputs than other models. HERA apart from emissions and fuel consumption produce carbon footprint and energy footprint outputs, which serve as tool for policy design and management of the highway (see Section 6).

\section{Basis of the HERA Methodology}

HERA follows a bottom-up approach for assessing the energy and carbon footprint of traffic flow in highway operation phase. It is divided into two modules. The first module assesses the energy and carbon footprint of highway traffic flow under different operating conditions. The second module focuses on the evaluation of energy consumption and $\mathrm{CO}_{2}$ emissions of toll plazas where traffic flow conditions are unique due to changes in and disruptions of driving conditions (Hernandez et al. 2013). This paper focuses on the first module.

The main features of the HERA methodology for highway operations are presented in Fig. 1. HERA integrates a consumption model with input databases in order to provide an original method for the estimation of the energy and carbon footprint of a highway. It allows efficient management of highway operation and gradient design through strategies which aim to reduce the energy and carbon footprint of a stretch of highway or an entire highway network.

Such policies and strategies can be applied by acting on the main input variables in order to achieve energy efficiency targets. Speed management; fleet renewal; heavy traffic flow management; or gradient design are the main strategies which could be 
Table 1 Revision of modeling approaches to assess emissions from road transport

\begin{tabular}{|c|c|c|c|c|c|}
\hline $\begin{array}{l}\text { Modeling } \\
\text { Approach }\end{array}$ & Spatial Scale & Emission Model & Data Input Requirements & Outputs Dimension & Main Application \\
\hline 1. Mensik et al. 2000 & Urban scale: Antwerp & $\begin{array}{l}\text { Aggregate emission factor: } \\
\text { COPERT }\end{array}$ & $\begin{array}{l}\text { Bottom-up: } \\
\text { input data per urban link }\end{array}$ & $\begin{array}{l}\text { Hourly air pollutant } \\
\text { emission }\end{array}$ & $\begin{array}{l}\text { Emission inventories } \\
\text { and yearly } \\
\text { comparison }\end{array}$ \\
\hline $\begin{array}{l}\text { 2. TEMMS (Namdeo et al. } \\
\text { 2002) }\end{array}$ & Urban scale & $\begin{array}{l}\text { Aggregated } \\
\text { emission factor: MEET }\end{array}$ & $\begin{array}{l}\text { Bottom-up: } \\
\text { input data per urban link }\end{array}$ & $\begin{array}{l}\text { Air pollutant emissions and } \\
\text { dispersion modeling }\end{array}$ & $\begin{array}{l}\text { Managing urban air } \\
\text { quality and scenario } \\
\text { assessment }\end{array}$ \\
\hline 3. Saija and Romano 2002 & Urban scale: Italy & $\begin{array}{l}\text { Aggregated } \\
\text { emission factor: COPERT }\end{array}$ & $\begin{array}{l}\text { Top-down: } \\
\text { input data per urban } \\
\text { scenario }\end{array}$ & Air pollutant emissions & Emission inventories \\
\hline $\begin{array}{l}\text { 4. TRAEMS } \\
\text { (Affum et al. 2003) }\end{array}$ & Urban scale & $\begin{array}{l}\text { Average speed model: } \\
\text { MOBILE }\end{array}$ & $\begin{array}{l}\text { Bottom-up: } \\
\text { input data per link }\end{array}$ & $\begin{array}{l}\text { Air pollutant, energy } \\
\text { consumption and } \mathrm{CO}_{2} \\
\text { emissions }\end{array}$ & Scenario assessment \\
\hline $\begin{array}{l}\text { 5. TREMOVE (De Ceuster } \\
\text { et al. 2004) }\end{array}$ & $\begin{array}{l}\text { Country } \\
\text { (under } \\
\text { Europe) }\end{array}$ & $\begin{array}{l}\text { Average speed model: } \\
\text { COPERT }\end{array}$ & $\begin{array}{l}\text { Top-down: } \\
\text { input data per scenario }\end{array}$ & $\begin{array}{l}\text { Fuel consumption, } \\
\text { pollutant emissions, } \\
\text { external cost factors }\end{array}$ & Policy assessment \\
\hline $\begin{array}{l}\text { 6. EMITRA } \\
\text { (Bellasio et at. 2007) }\end{array}$ & $\begin{array}{l}\text { Regional \& urban scale: } \\
\text { Italy }\end{array}$ & $\begin{array}{l}\text { Aggregated emission factor: } \\
\text { COPERT }\end{array}$ & $\begin{array}{l}\text { Bottom-up: } \\
\text { input data per link }\end{array}$ & Annual air pollutant emissions & Emission inventories \\
\hline $\begin{array}{l}\text { 7. EMITRANS (Lumbreras } \\
\text { et al. 2009) }\end{array}$ & Country & $\begin{array}{l}\text { Average speed model: } \\
\text { COPERT }\end{array}$ & $\begin{array}{l}\text { Top-down: } \\
\text { input data per scenario }\end{array}$ & $\begin{array}{l}\text { Air pollutant emissions by } \\
\text { scenario }\end{array}$ & Policy assessment \\
\hline 8. HERA & Highway alignments & $\begin{array}{l}\text { Average speed model adjusted } \\
\text { with segment gradient: } \\
\text { based on COPERT factors } \\
\text { database }\end{array}$ & $\begin{array}{l}\text { Bottom-up: } \\
\text { input data per link }\end{array}$ & $\begin{array}{l}\text { Annual fuel consumption, } \\
\text { energy footprint and } \\
\text { carbon footprint }\end{array}$ & $\begin{array}{l}\text { Managing efficient } \\
\text { highway } \\
\text { operation, } \\
\text { design and scenario } \\
\text { assessment }\end{array}$ \\
\hline
\end{tabular}




\section{HERA}

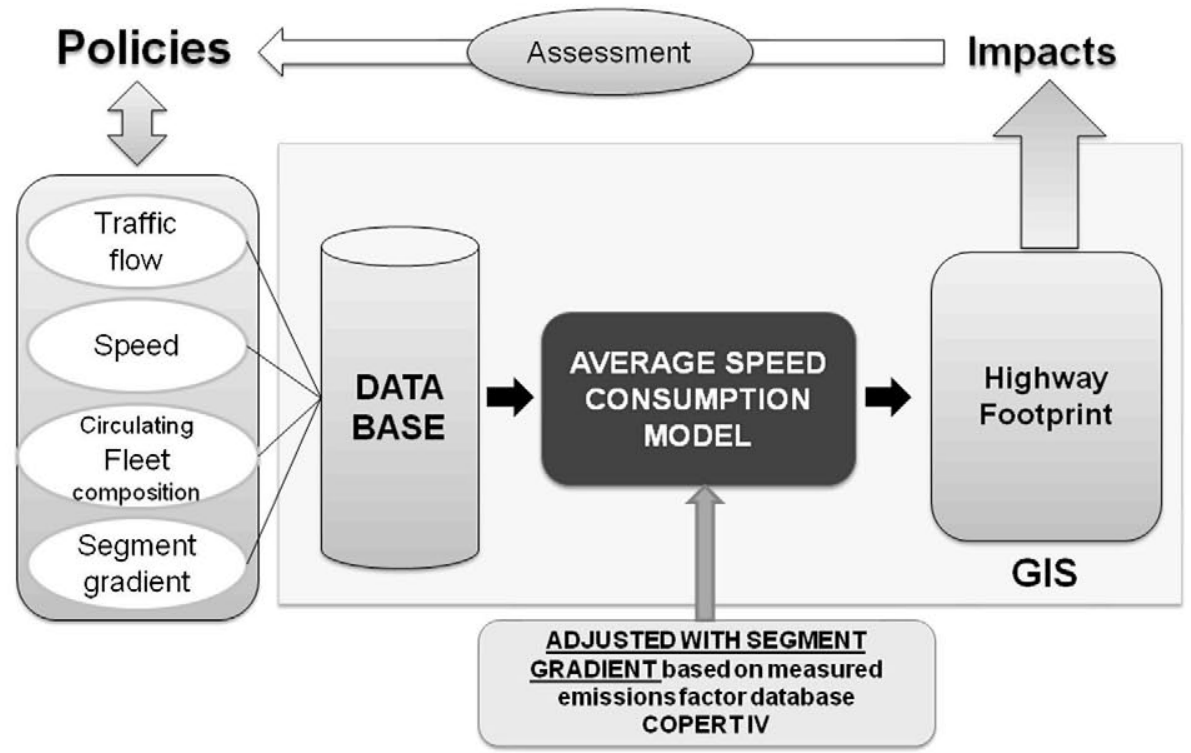

Fig. 1 Architecture of the HERA methodology module 1: highway operations

evaluated by using HERA. It can analyze the effect of each measure over the final energy and carbon footprint of the highway.

The calibration and adjustment of the consumption model is one of the main benefits of this methodology (see Section 4). Apart from fuel consumption, it estimates the energy and carbon footprint of highway traffic flow. The assessment of the carbon and energy impacts of a policy can provide an objective measure of its effectiveness. Furthermore, a Geographical Information System (GIS) can support the input and output data, providing a geographic representation of the energy and carbon footprint.

The application of the HERA methodology consists of the following phases for each considered scenario (Fig. 2): (1) division of the selected highway into segments classified as homogeneous - using aggregation methods based on the number of lanes, gradient, average annual daily traffic (AADT), speed, percentage of heavy-duty vehicles, etc. (Koorey 2009) - and introduction of input data; (2) application of the consumption model to each segment of highway; (3) aggregation of all footprint results of each segment for the whole highway under consideration; (4) geographic representation of highway footprint supported by a GIS (this option is available only if the segment is geo-referenced).

In the first phase, information is collected regarding the fleet composition, as well as physical and traffic flow characteristics of all stretches of highway. Segment gradient, number of lanes, length, AADT, vehicle fleet composition, and mean speed by vehicle category are the main variables used in the consumption model. This data collection could be obtained either from real data collection in the road or through traffic demand simulation techniques (Nökel and Schmidt, 2002; Taylor, 2003). Planners, decisionmakers, and operators can act directly on these variables by means of energy-efficient highway management policies (Monzon et al. 2012). Moreover, national traffic maps as 


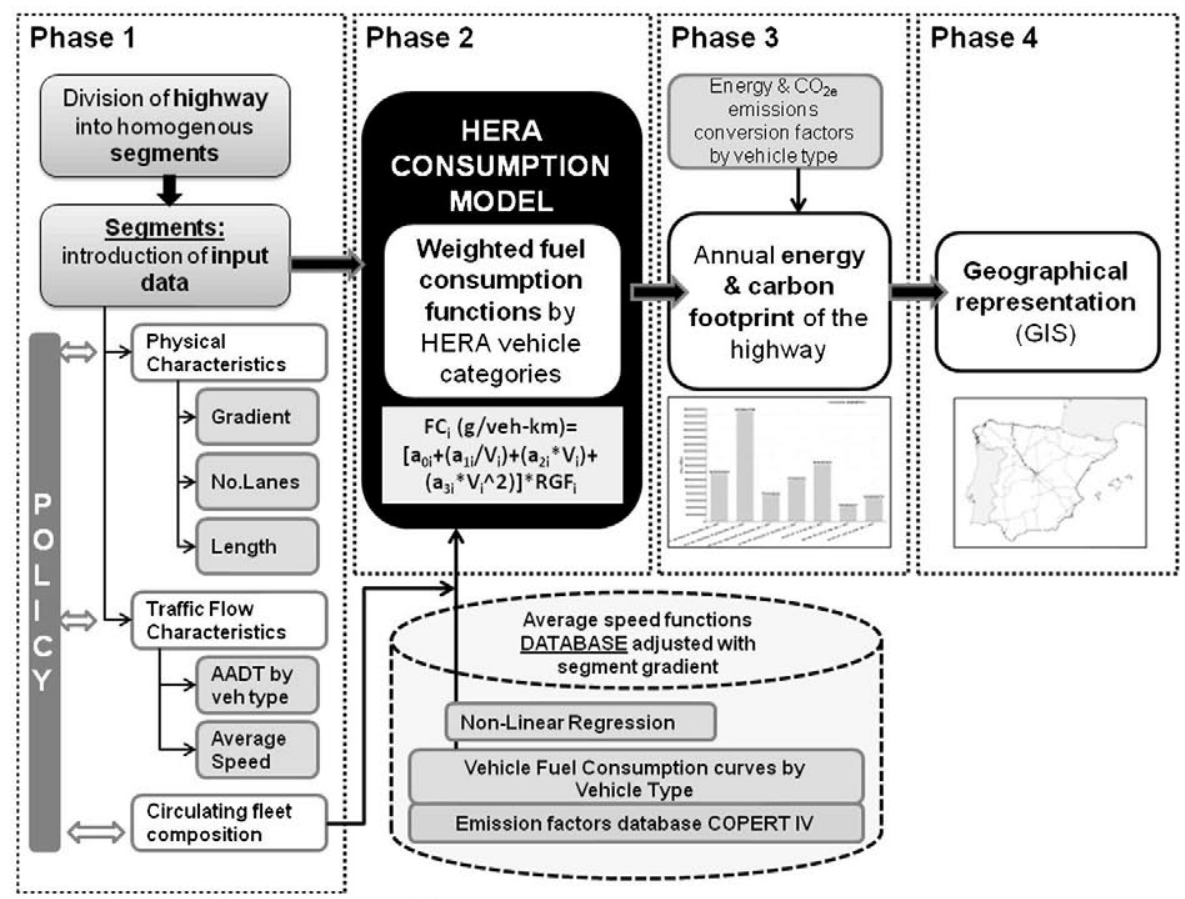

Fig. 2 Phases of the HERA methodology

well as transportation network information modeled in a GIS environment provide georeferenced data that can easily be entered into the HERA methodology database. The second phase consists of the application of the consumption model to each stretch of highway. In the third phase, the estimated fuel consumption is multiplied by an energy and carbon factor in order to calculate the footprint of the different stretches of highway over a year. Finally, the highway footprint is mapped with a GIS.

\section{Consumption Model Description}

\subsection{Average Speed Consumption Model Adjusted with Road Gradient}

Average speed is a key factor in vehicles' consumption and emissions output. Several studies have found that the relationship between the specific consumption and vehicle speed is U-shaped (Andre and Hammarstrom 2000; Smit et al. 2008). Therefore, it is possible to develop speed-based consumption factors (grams of fuel per kilometer) simply by using traffic flow records as input data for the emission model.

The HERA consumption model (Phase 2) is based on consumption and emission factors from COPERT IV (Gkatzoflias et al. 2007). It has also been adjusted to include MEET (Methodologies to Estimate Emissions from Transport) guidelines, which have been widely adopted at a European level (Hickman et al. 1999). To estimate the consumption and emission factors, COPERT IV takes into account the fuel type, engine capacity and engine technology for light vehicles and the maximum total weight, load 
state, engine technology and road gradient for heavy vehicles. Furthermore, COPERT provides different consumption factor algorithms based on 2 or 3 speed ranges by vehicle type.

In order to obtain a single average consumption curve by vehicle category, the HERA consumption model is based on an adaptation of the Bennet and Greenwood (2001) fuel consumption equation.

HERA uses average speed as the main factor and the road gradient as a correction factor instead of as an addend (Eq. 1). HERA considers six vehicle categories $i$ : passenger cars, light-duty vehicles, motorcycles, rigid trucks, articulated trucks, and buses.

$$
F C_{i}(\mathrm{~g} \text { fuel/veh-km })=\sum i\left[a_{0, i}+\left(a_{1, i} / V_{i}\right)+\left(a_{2, i} * V_{i}\right)+\left(a_{3, i} * V_{i}^{2}\right)\right] * R G F_{i}
$$

Where $F C_{i}$ is the fuel consumption factor of the vehicle category $i ; a_{0, i} ; a_{1, i} ; a_{2, i} ; a_{3, i}$ are calibrated parameters which depend on the vehicle category $i ; V_{i}$ is the average speed of the vehicle (expressed in kilometers per hour) and $R G F_{i}$ is the road gradient correction factor for light vehicles. Hence, the model adjustment with the road gradient effect is an added value in the consumption model, as explained in the following subchapter.

\subsubsection{Road Gradient Effect}

Vehicle emission modeling includes the road gradient as an important variable in the estimation of $\mathrm{CO}_{2}$ emissions and energy consumption. The gradient of a road has the effect of increasing or decreasing the resistance of a vehicle to traction. This increase or decrease in the load on the engine has a corresponding effect on emissions and energy consumption rates (Hassel and Weber 1997). Furthermore, it has not been established that the over-consumption caused by traveling uphill is compensated for by the reduced consumption when traveling downhill. Some studies have researched the influence of road grades on energy consumption and emissions in real-life experiments (Pierson et al. 1996; Cicero Fernandez et al. 1997; Colberg et al. 2005; Tsang et al. 2011) and some approaches have been developed from the experimental experiences (Hassel and Weber 1997; Park and Rakha 2006; Boriboonsomsin and Barth 2009; Shuangjian et al. 2011). Park and Rakha (2006) demonstrated that the impacts of road gradients are significant. For example, the fuel consumption and $\mathrm{CO}_{2}$ emissions for a normal light-duty vehicle under cruising conditions are increased by $148 \%$ and $139 \%$, respectively, as result of a $6 \%$ increase in road grade. In addition, the influence of the gradient on emissions also depends on speed.

The gradient effect is considered in the HERA consumption module. In the case of heavy vehicles, it is already included in the consumption factor functions (Section 4.2). For light vehicles, however, the gradient effect is incorporated as a gradient correction factor based on a polynomial function of the vehicle's mean speed by engine technology and vehicle category (Hickman et al. 1999). The road gradient factor considered in Eq. 1 has the following formulation:

$$
R G F_{i}=A 6_{i, k} * V^{6}+A 5_{i, k} * V^{5}+A 4_{i, k} * V^{4}+A 3_{i, k} * V^{3}+A 2_{i, k} * V^{2}+A 1_{i, k} * V+A 0
$$


Where $R G F_{i}$ is the road gradient correction factor for the light vehicle category $i$, V is the mean speed (expressed in kilometers per hour) and A0 to A6 are the coefficients provided by Hickman et al. (1999) which depend on the road gradient.

As a result, HERA provides an advantageous average speed consumption model which is adjusted considering the road gradient effect. The HERA approach includes a database which collects all consumption model functions by vehicle type. The following Section 4.2. describes the procedure that has been followed to obtain the consumption model database.

\subsection{Consumption Model Procedure}

The procedure for obtaining the HERA consumption model consists of four steps. From Step 1 to 3, it is presented the establishment of the HERA consumption model database. Step 4 implies the adaptation of the consumption model to the case study under assessment based on the circulating fleet of the highway.

Step 1 Collection of consumption factors by vehicle type and speed range from COPERT IV database.

The COPERT IV database provides consumption factor algorithms by vehicle type and speed range. HERA incorporates a total of 183 vehicle types from COPERT IV: 77 light vehicle types divided by fuel type, engine capacity, and engine technology, and 96 heavy-duty vehicle types classified by maximum total weight, load state, engine technology, and road gradient. Based on these data, HERA offers 93 consumption factor equations for light vehicles and 2,205 for heavy vehicles. The substantial difference in the number of equations, between light and heavy vehicles, can be explained by the fact that COPERT considers different gradients $(0 \%, 2 \%, 4 \%, 6 \%$, $-2 \%,-4 \%$, and $-6 \%$ ) and load factors (unloaded, semi-loaded, and fullyloaded), but only for heavy vehicles.

Step 2 Establishment of fuel consumption curves based on speed for each vehicle type.

For each vehicle type and speed value, fuel consumption factors are obtained using COPERT algorithms by speed range. These values are then represented as fuel consumption curves (see the example of a gasoline passenger car with an engine smaller than 1.4 liters in Fig. 3).

Step 3 Customization of the curve of each vehicle type to Eq. 1.

Each consumption curve from Step 2 is customized to the Eq. 1 by using non-linear regression techniques. This step involves the parameterization of the consumption curves described above in order to obtain the HERA consumption model function for each vehicle type. A statistical software (SPSS) has been used for the parameterization of all curves. All the consumption equations generated during this process are recorded in the HERA database. HERA consumption model equations database is the based framework which supports the HERA methodology.

Step 4 Adapting HERA to a specific highway case study

Finally, the adaptation of HERA to a specific case study consists on the estimation of the average consumption functions for each 


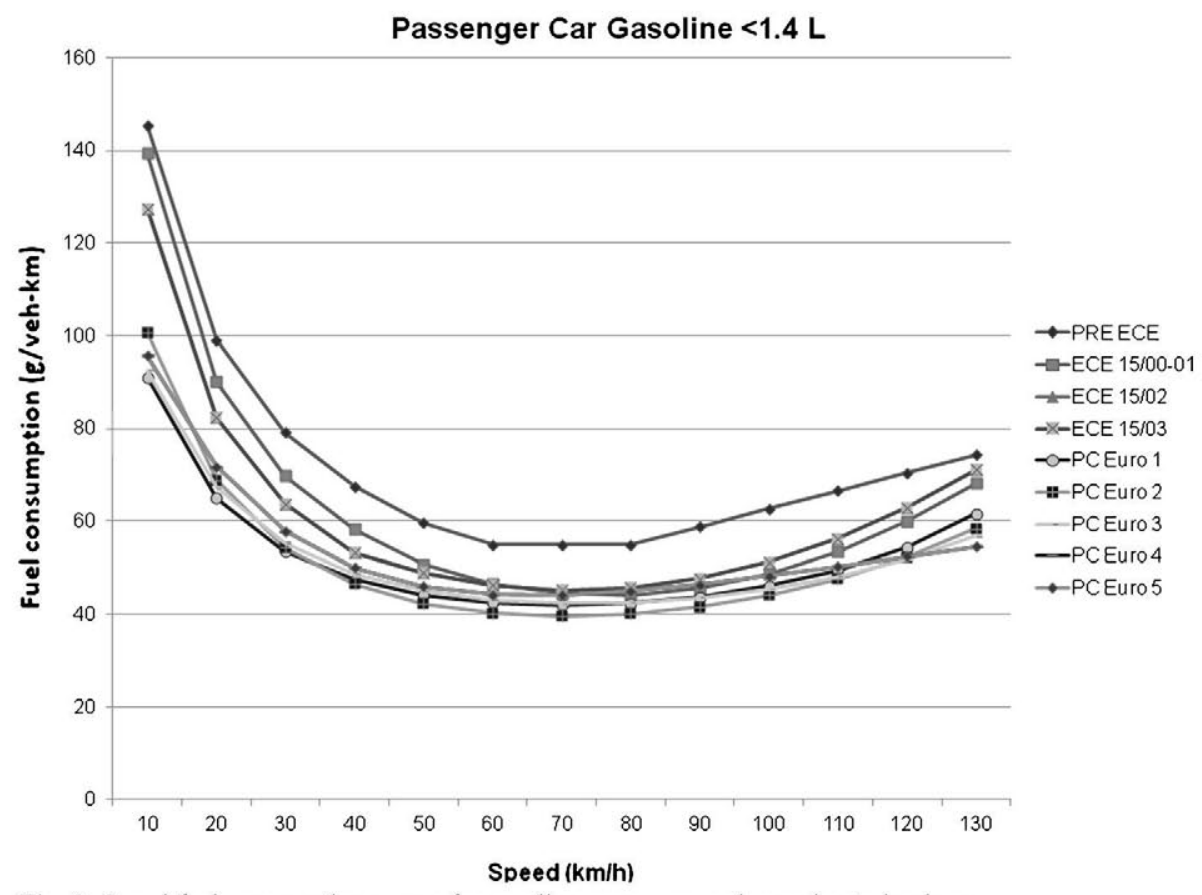

Fig. 3 Speed-fuel consumption curves for gasoline passenger car by engine technology

vehicle category. To this end, weighting parameters are calculated on the basis of the circulating vehicle fleet composition. The weighting parameters are the proportion of each vehicle type of the circulating fleet.

Circulating fleet refers to the real number of vehicles using the highway. Hence, before obtaining the weighting parameters, the fleet composition must be adjusted taking into account the fact that the number of highway kilometers traveled in highways decreases with the vehicle's age (Burón et al. 2005). Some previous studies have considered mileage correction factors. Hickman et al. (1999) included vehicles' annual mileage as a correction factor for fleet composition. Borken et al. (2000) proposed a method in which a new vehicle counts as one unit while an older vehicle counts as a fraction of a unit: the older the vehicle, the smaller the fraction. Logghe et al. (2006) used a mileage factor in order to calculate traffic flow emissions. Most recently, Ntziachristos et al. (2008) justified the importance of taking into account the annual mileage factor and proposed a method to estimate an annual mileage factor. HERA incorporates the Ntziachristos et al. annual mileage factors in order to establish the actual composition of the current circulating fleet.

Finally, these weighting parameters are applied to the equations obtained in Step 3 to establish the average consumption function by each vehicle category. In this way, the full list of HERA consumption functions is simplified to a limited number of vehicle 
categories, normally corresponding to the official categories used for vehicle registration in each country or region.

\section{Validating HERA for the Spanish Highway Network}

\subsection{HERA Applied to the Spanish Highway Network}

The application of the HERA methodology to the network of a specific country or region - in this case Spain -, starts with the characterization of the circulating fleet composition (obtaining weighting parameters, Step 4 of the modeling framework). The Spanish vehicle fleet composition offered by official institutions does not differentiate between the highway fleet and the fleet which uses other types of roads. Hence, the Spanish fleet composition database must be corrected in order to represent the real circulating fleet, in this case, those vehicles which circulate on highways.

The annual Spanish mileage factors provided by Ntziachristos et al. (2008) for each type of vehicle have been incorporated in order to obtain the mileage correction factor required to adapt the HERA consumption model to the Spanish case study. Figure 4 offers an example of the annual mileage correction factor for a gasoline passenger car. In this case, until six years-old, there is no correction, being the mileage correction factor one. Then, the mileage correction factor decreases to 0.87 for 10 years-old, and to 0.70 for 15 years-old cars.

The application of the annual mileage correction factors to the vehicle fleet establishes the composition of the circulating vehicle fleet of the Spanish highway network.

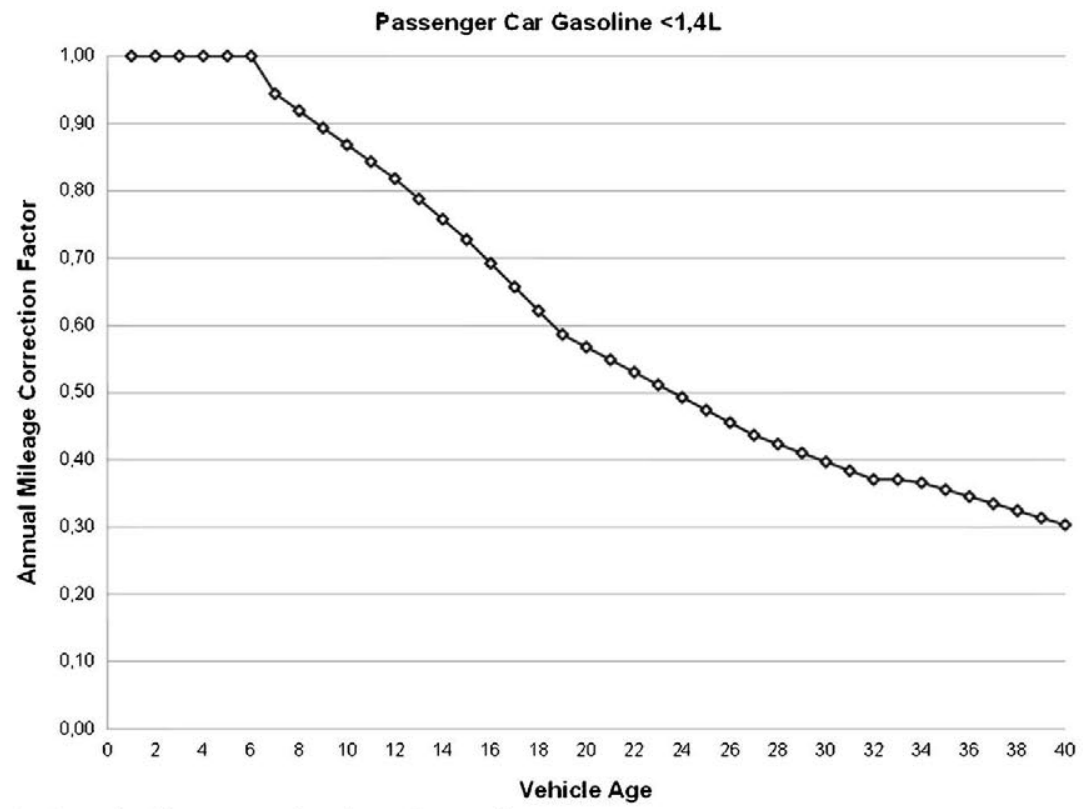

Fig. 4 Annual mileage correction factor for gasoline passenger car 
Table 2 Composition of circulating vehicle fleet of Spanish highway network in $2009(\%)$

\begin{tabular}{lcllllr}
\hline $\begin{array}{l}\text { Engine } \\
\text { Technology }\end{array}$ & Motorcycle & $\begin{array}{l}\text { Passenger } \\
\text { Car }\end{array}$ & $\begin{array}{l}\text { Light-Duty } \\
\text { Vehicles }\end{array}$ & $\begin{array}{l}\text { Rigid } \\
\text { Truck }\end{array}$ & $\begin{array}{l}\text { Articulated } \\
\text { Truck }\end{array}$ & Bus \\
\hline EURO IV & - & 36.31 & 23.79 & 41.76 & 39.57 & 35.28 \\
EURO III & 55.98 & 33.31 & 25.65 & 33.64 & 38.20 & 27.89 \\
EURO II & 8.49 & 13.73 & 15.80 & 17.34 & 12.24 & 21.77 \\
EURO I & 3.38 & 7.64 & 12.60 & 2.08 & 2.08 & 5.27 \\
PREEURO & 32.15 & 9.01 & 22.16 & 5.09 & 7.91 & 9.79 \\
\hline
\end{tabular}

Table 2 shows the proportion of each HERA vehicle category by engine technology. It can be observed that the heavier vehicles have a larger percentage of newer engines ( $35 \%-40 \%$ of heavy vehicles are EUROIV), while the fleet of light-duty vehicles and motorcycles is much older ( $30 \%$ of motorcycles and $22 \%$ og light-duty vehicles are PREEURO).

Finally, the application of the weighting parameters to the calibrated equations (Step 4 of the consumption model) produces the HERA consumption functions for each of the six vehicle categories considered. The following Table 3 includes the weighted average fuel consumption functions for each vehicle category of the circulating Spanish fleet in 2009 with a road grade of zero ( $R G F=1$ for light vehicles) based on average speed $(\mathrm{km} / \mathrm{h})$.

\subsection{Validation of the HERA Consumption Model in the Case of Spain}

Model validation is defined as the comparison of predictions with independent observations. These observations are obtained by a variety of methods, including on-board measurements. This method provides reasonable control over influencing factors (cold start, vehicle loading, gradient, etc.).

The emissions factors estimated using the HERA consumption functions were compared with the total emission level measurements obtained by the on-board devices over the corresponding distance.

Smit et al. (2010) discussed the validation of different types of traffic emission models, including average speed models. Their results demonstrate that testing the overall accuracy of road traffic emission models is difficult, and only partial model validation is feasible (Smit et al. 2010). Consequently, in this section a partial

Table 3 Fuel consumption function by HERA vehicle type

\begin{tabular}{ll}
\hline Vehicle Type & Fuel Consumption Function for 0\% Road Gradient (gfuel/veh-km) \\
\hline Motorcycle & $\mathrm{FC}=25.722+(276.13 / \mathrm{V})+(-0.254) * \mathrm{~V}+0.00311^{*} \mathrm{~V}^{2}$ \\
Passenger Car & $\mathrm{FC}=54.7+(496 / \mathrm{V})+(-0.542) * \mathrm{~V}+0.0042 * \mathrm{~V}^{2}$ \\
Light-Duty Vehicle & $\mathrm{FC}=146.27+((-0.0000106) / \mathrm{V})+(-2.596)^{*} \mathrm{~V}+0.01984 * \mathrm{~V}^{2}$ \\
Rigid Truck & $\mathrm{FC}=152.96+(604.156 / \mathrm{V})+(-2.295)^{*} \mathrm{~V}+0.0238^{*} \mathrm{~V}^{2}$ \\
Articulated Truck & $\mathrm{FC}=332.603+(1680.879 / \mathrm{V})+(-4.676)^{*} \mathrm{~V}+0.0311^{*} \mathrm{~V}^{2}$ \\
Bus & $\mathrm{FC}=281.735+(4186.178 / \mathrm{V})+(-3.457) * \mathrm{~V}+0.0216^{*} \mathrm{~V}^{2}$ \\
\hline
\end{tabular}


validation of the HERA methodology is presented, considering the on-board data collected during a number of real case studies.

The data used for the HERA validation were collected on three different routes with a gasoline light-duty vehicle equipped with a portable emissions and consumption control device (Horiba OBS 2200) and additional devices to measure speed (L-CE Correvit sensor), acceleration, road gradient (ADMA gyroscope), and time. The measurements were performed during March 2011. Below, Fig. 5 illustrates the different routes used. These routes were selected for the measurements as they all experience heavy traffic flow and have stretches with different gradients. Each of the routes was divided into segments with homogeneous road gradient, speed characteristics, traffic flow and number of lanes.

a

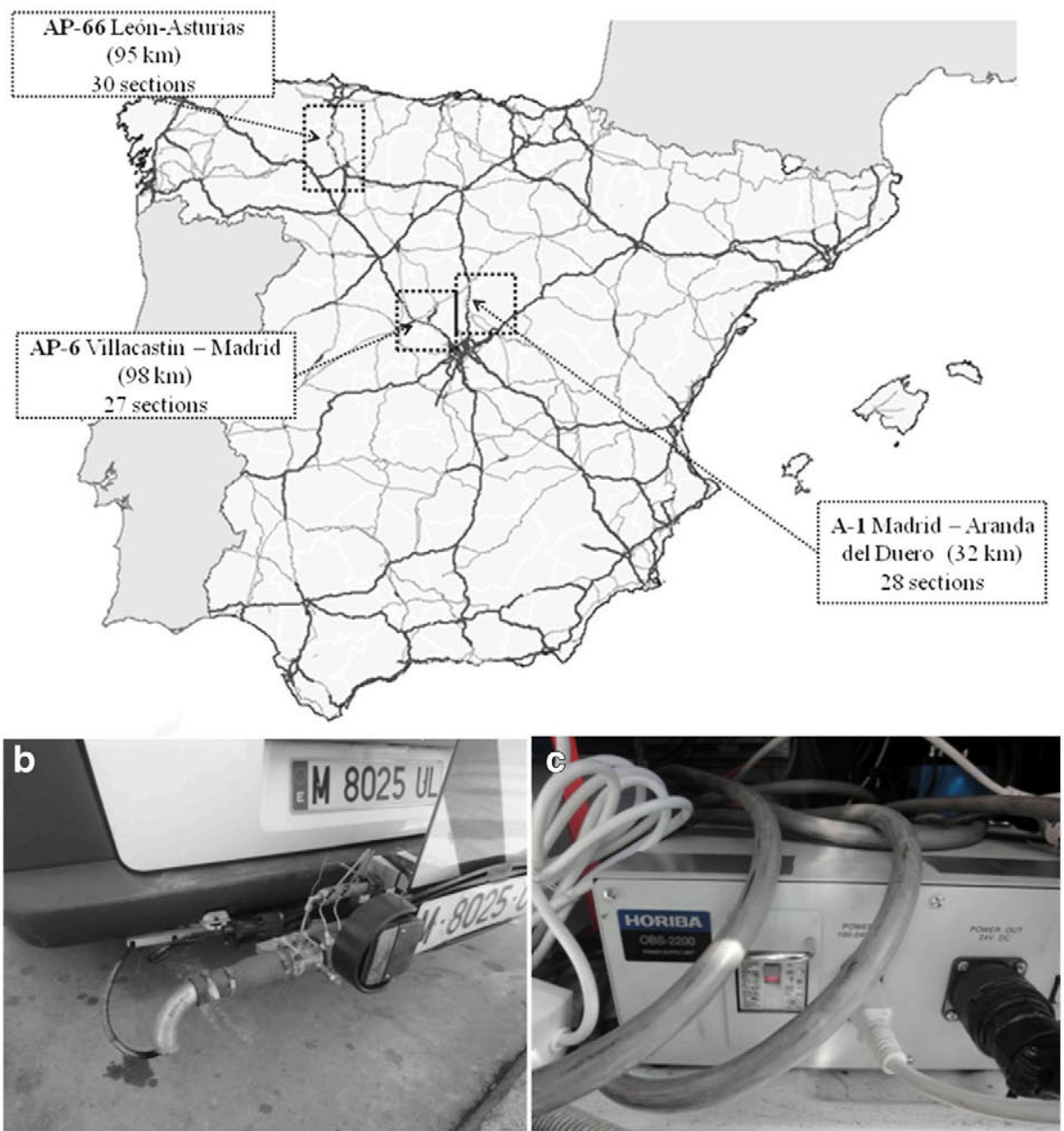

Fig. 5 a Spanish highway network with routes selected for HERA tool validation. b, $\mathbf{c}$ Portable emission and consumption device: Horiba OBS 2200 
The mean prediction error was used to assess the difference between the emissions values predicted by HERA and those observed in the validation test. The mean difference between the predicted and observed values of a validation sample is the most important criterion for determining whether a model works well in practice (Fomunung et al. 2001; Smit et al. 2010). The mean prediction error is quantified using the following equation $(\varepsilon, \%)$ :

$$
\varepsilon=100 *[(\bar{U}-\bar{O}) / \bar{O}]
$$

Where $\bar{U}$ is the predicted value and $\bar{O}$ is the observed value. In addition to the mean prediction error, the linear correlation coefficient was also determined to assess the performance of the HERA consumption model.

\subsubsection{Results of HERA Validation}

This section describes the results of the validation of the HERA methodology by comparing the estimated $\mathrm{CO}_{2}$ emissions values to a set of observed data from the onboard measurements. Figure 6a presents the values obtained from HERA and measured values during the real-life test with on-board equipment. As can be seen, predicted values tend to be slightly smaller than the measured values, similar to what happened in the comparison of other emissions simulation models to real measurement (Silva et al. 2006).

a
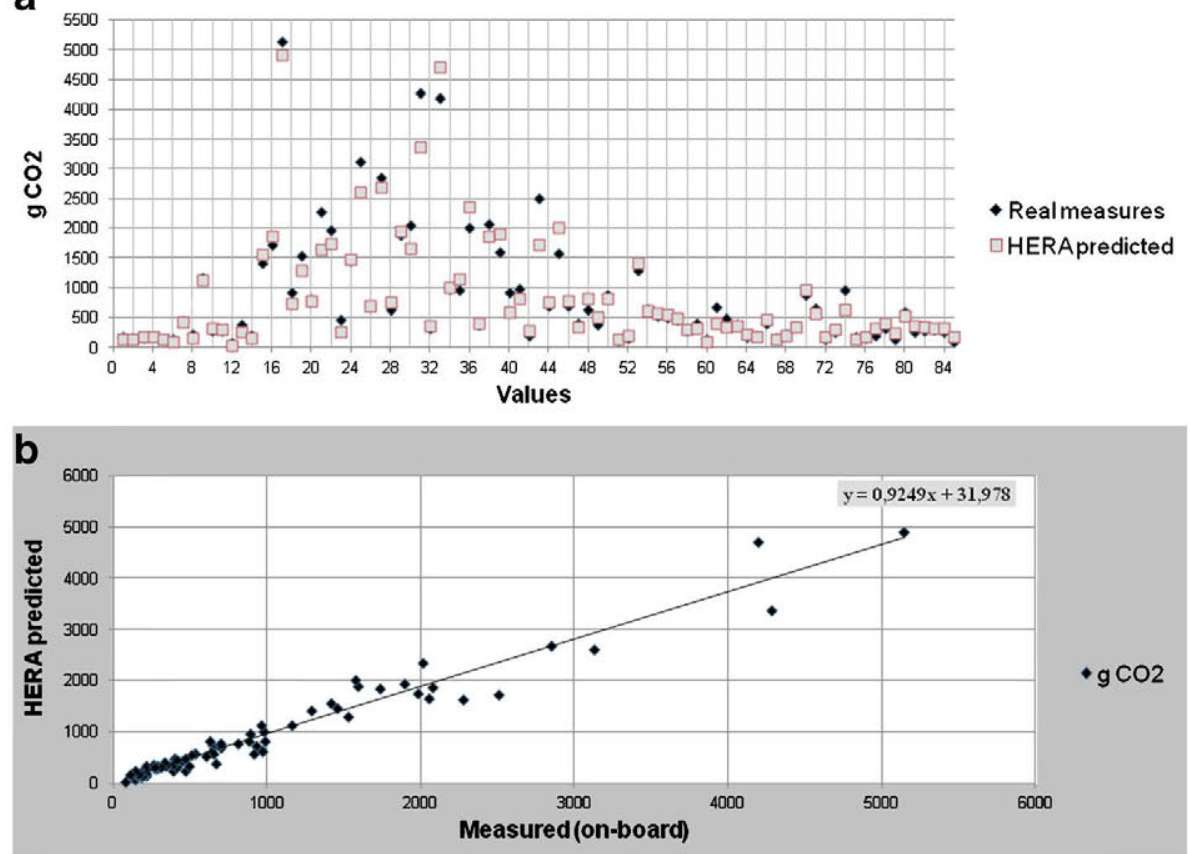

Fig. 6 a Measured and predicted $\mathrm{CO}_{2}$ emissions values. b Comparison between measured and estimated $\mathrm{CO}_{2}$ emissions values 
Figure $6 \mathrm{~b}$ offers the statistical analysis of the estimated and measured $\mathrm{CO}_{2}$ emissions on all routes. The linear correlation is high $(\mathrm{r}=0.97)$ which reflects a good relationship between the predicted and measured values. The slope coefficient is less than $1(0.92)$, which indicates that the emissions values estimated by the HERA model are lower than those determined by the on-board measurements. The value of the mean prediction error for all the measurements, determined by applying Eq. 3, was $-3.79 \%$ which means that the model performed quite well. However, as previously stated, these results only partially validate the HERA approach

Finally, from the on-board measurements, it has been obtained that stretches with $3 \%$ slope results in a vehicle's overconsumption of $30 \%$ in relation with flat road sections, at the same average speed. Justifying, the adjustment with the gradient effect of HERA average speed consumption model and being in line with the studies reviewed in Section 4.1.1.

\section{HERA Application Case Study: Footprint Assessment of AP-66 Motorway and Scenario Comparison}

A case study was devised to validate the HERA methodology's footprint assessment capabilities using 2009 data from the AP-66 toll motorway in northern Spain. The chosen route is $77.3 \mathrm{~km}$ long. The input data variables were derived from two sources: the AADT and the speed data were obtained from the 2009 Spanish Traffic Map (MF 2010); the road gradient and speed characteristics used to divide the route into homogenous segments were obtained from the on-board measurements (explained in the validation section), though it would have been possible to calculate these data by joining a traffic maps to a topographic map in a GIS environment.

The application of the HERA methodology has several benefits, including the possibility of assessing scenarios based on different management strategies. In order to evaluate the methodology, two policy scenarios - a speed management scenario and a highway alignment improvement scenario - were created to estimate their effects on the carbon and energy footprint of the AP-66.

The reference scenario is characterized by an AADT of 4,978 veh/day and an average speed of $117 \mathrm{~km} / \mathrm{h}$ for light vehicles and $97 \mathrm{~km} / \mathrm{h}$ for heavy vehicles. The speed management scenario was tested by calculating the impact of a $10 \mathrm{~km} / \mathrm{h}$ speed reduction for light vehicles on the toll motorway. The highway alignment improvement scenario considered the same highway section than the reference one (same vehicle distribution and average speed) but with $0 \%$ slope. These two hypothetical scenarios were compared to a reference scenario based on the actual 2009 AP- 66 speed and alignment data. The results show the potential emissions savings of both management options. Finally, all the data were mapped using a GIS to produce a geographic representation.

The outcomes obtained from the HERA application to the case study are shown in the Table 4 . The results also indicate the contribution by vehicle category (light and heavy). The energy and carbon footprint have been calculated for a period of one year 
Table 4 Energy and carbon footprint results of HERA tool application to AP-66 motorway case study

\begin{tabular}{|c|c|c|c|}
\hline Scenario Description & $\begin{array}{l}\text { Energy Footprint } \\
\text { Results (G.J/year) }\end{array}$ & $\begin{array}{l}\text { Carbon Footprint Results } \\
\left(\mathrm{T} \mathrm{CO}_{2 \mathrm{e}} / \text { year }\right)\end{array}$ & $\begin{array}{l}\text { Carbon Footprint } \\
\text { Savings }(\%)\end{array}$ \\
\hline AP-66 Reference Scenario (2009) & $1,119,125$ & $96,819.4$ & - \\
\hline Light vehicles & 589,821 & $50,221.0$ & - \\
\hline Heavy vehicles & 529,304 & $46,597.9$ & - \\
\hline $\begin{array}{l}\text { Speed Management Scenario: } \\
\text { AP-66 Light Vehicle Speed } \\
\text { Reduction }-10 \mathrm{~km} / \mathrm{h}(2009)\end{array}$ & $1,068,304$ & $92,485.9$ & $4.5 \%$ \\
\hline Light vehicles & 539,000 & $45,880.0$ & - \\
\hline Heavy vehicles & 529,304 & $46,597.9$ & - \\
\hline $\begin{array}{l}\text { Highway Alignment Improvement } \\
\text { Scenario: } \\
\text { AP-66 Highway Gradient Design } \\
0 \%(2009)\end{array}$ & 967,093 & $83,576.5$ & $13.7 \%$ \\
\hline Light vehicles & 540,7333 & $46,041.4$ & - \\
\hline Heavy vehicles & 426,360 & $37,535.1$ & - \\
\hline
\end{tabular}

for all three scenarios. As other studies have demonstrated (Dijkema et al. 2008; Panis et al. 2011), speed management strategies are environmentally-effective options. The AP-66 speed reduction scenario resulted in annual carbon footprint savings of $4.5 \%$ over the total. Additionally, the findings show that proper design is a key element in

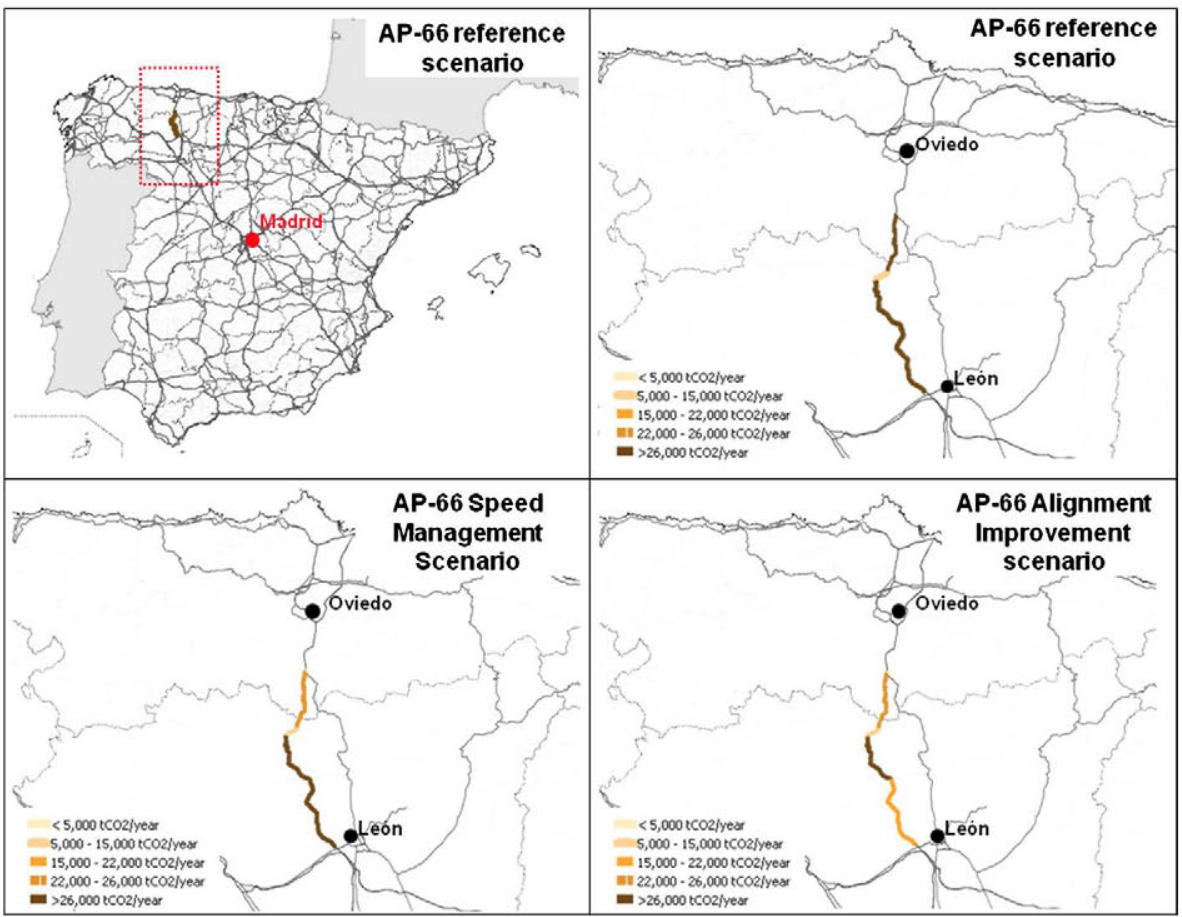

Fig. 7 Geographic representation of estimated carbon footprint results of stretches of the AP-66 motorway 
improving the energy and carbon efficiency of a highway in the operational phase. A highway which avoids hilly areas is more sustainable in the operational phase; the improved highway design scenario achieved an annual carbon footprint savings of $13.7 \%$ with respect to the reference scenario. A geographic representation of the estimated carbon footprint for each scenario is included in Fig. 7 and illustrates the possible effects of the proposed policies on the highway's footprint.

\section{Conclusions}

Emissions reduction and energy efficiency are key policy elements for managing roads (Ison and Wall 2003). This paper presents a sequential methodology called HERA - Highway EneRgy Assessment -developed to assess the energy and carbon footprint of highway operations. HERA is a methodology which integrates a consumption model with input databases to estimate the annual footprint of traffic flows for a specific stretch of highway or an entire network. The main added value of HERA methodology is that its consumption model based on the COPERT emission factors- incorporates a correction factor to include the effect of the gradient of each road section.

We have validated the HERA methodology through the application to the Spanish highway network. It has been proved that it estimates the carbon footprint vehicles with sufficient accuracy.

HERA is valid for every country or region and for every highway segment or network. It requires specific input data corresponding to each individual case study. However, the necessary data inputs - vehicle fleet composition, annual mileage, gradient, number of lanes, length, AADT, and average speed - are normally available in transportation databases. By acting on these main input variables (speed, fleet composition, traffic flow, gradient), different policies and strategies can be proposed and tested in order to achieve energy efficiency and carbonless objectives. The assessment is based on the comparison of the footprint for different scenarios with the reference to a base year.

Hence, HERA allows a better design and assessment of policies -both during the planning and design phases- and management strategies focused on achieving significant reductions in energy consumption and GHG emissions during the operational phase. It is of particular interest for policies and strategies focused on alignment design, speed adjustment, traffic flow management or fleet composition. The estimation of the footprint of AP-66 motorways using different strategies (traffic management and alignment improvement) has evidenced that the tool can successfully compare scenarios in order to assess transport policies. For instance, improving the alignment of the road could result in $13.7 \%$ of annual carbon footprint. In addition, the speed management such as speed reduction for light vehicles could save $4.5 \%$ of the annual carbon footprint. Lastly, there is also presented the HERA GIS capabilities (i.e. use of georreference segments for input and output).

Therefore, HERA provides basis for future emission models' improvements. The follow-up of this research could include the following topics. 
a) A more detailed analysis of the effect of the gradient in vehicles' emissions. It should be based on real measurement campaigns. Then, the correction factor of HERA consumption model will be of wider application.

b) Further development of HERA could provide specific footprint assessment for different types of road under different driving conditions. Therefore, obtaining an energy and carbon efficiency indicator for each road category may help to a more sustainable management of traffic.

c) HERA methodology has been applied to a Spanish case study. Carbon footprint optimization of traffic motorway networks will provide valuables results for energy and environmental challenges. This would be covered by using HERA in the assessment of different strategies and comparison of scenarios in specific case studies.

In conclusion, HERA generates the necessary information for managing decarbonization targets and improving energy efficiency, both in planning and operating highway networks. Future research could improve its capabilities for assessing footprint in a number of different applications.

Acknowledgments The HERA tool forms part of the OASIS project funded by the CENIT research program (CEN-20081016) of the Spanish Ministry of Science and Technology. The authors would also like to thank the Dirección General de Tráfico (DGT), the AP-66 toll motorway operator AVASA, the Institute for Automobile Research (INSIA) for their contribution in obtaining the on-board measurements, and all reviewers for their valuable comments.

\section{References}

Affum J, Brown A, Chan Y (2003) Integrating air pollution modelling with scenario testing in road transport planning: the TRAEMS approach. Sci Total Environ 312(1-3):1-14. doi:10.1016/S0048-9697(03)00192$\mathrm{X}$

Ando N, Taniguchi E (2006) Travel time reliability in vehicle routing and scheduling with time windows. Netw Spat Econ 6(3-4):293-311. doi:10.1007/s11067-006-9285-8

Andre M (2004) The ARTEMIS European driving cycles for measuring car pollutant emissions. Sci Total Environ 334:73-84. doi:10.1016/j.scitotenv.2004.04.070

Andre M, Hammarstrom U (2000) Driving speeds in Europe for pollutant emissions estimation. Transp Res Part D-Transp Environ 5(5):321-335. doi:10.1016/S1361-9209(00)00002-X

Banister D (2012) Transport and economic development: reviewing the evidence. Transp Rev 32(1):1-2. doi: $10.1080 / 01441647.2011 .603283$

Bellasio R, Bianconi R, Corda G, Cucca P (2007) Emission inventory for the road transport sector in Sardinia (Italy). Atmos Environ 41(4):677-691. doi:10.1016/j.atmosenv.2006.09.017

Bennet CR, Greenwood ID (2001) Modelling road user and environmental effects in HDM-4. World Road Association (PIARC), Paris/The World Bank, Washington, D.C.

Boriboonsomsin K, Barth M (2009) Impacts of Road Grade on Fuel Consumption and Carbon Dioxide Emissions Evidenced by Use of Advanced Navigation Systems. Transp Res Rec 2139:21-30. doi:10. 3141/2139-03

Borken J, Knörr W, Höpfner U (2000) Energy consumption and pollutant emissions from road transport in Belgium 1980 to 2020. Insitut für Energie und Umweltforschung Heidelberg (IFEU), Heidelberg

Burón JM, Aparicio F, Izquierdo Ó, Gómez Á, López I (2005) Estimation of the input data for the prediction of road transportation emissions in Spain from 2000 to 2010 considering several scenarios. Atmos Environ 39(30):5585-5596. doi:10.1016/j.atmosenv.2005.06.013

Chi G, Stone B (2005) Sustainable transport planning: Estimating the ecological footprint of vehicle travel in future years. J Urban Plan Dev-Asce 131(3):170-180. doi:10.1061/(ASCE)0733-9488(2005)131:3(170) 
CiceroFernandez P, Long J, Winer A (1997) Effects of grades and other loads on on-road emissions of hydrocarbons and carbon monoxide. J Air Waste Manage Assoc 47(8):898-904

Colberg C, Tona B, Stahel W, Meier M, Staehelin J (2005) Comparison of a road traffic emission model (HBEFA) with emissions derived from measurements in the Gubrist road tunnel, Switzerland. Atmos Environ 39(26):4703-4714. doi:10.1016/j.atmosenv.2005.04.020

Commission E (2010) EU energy and transport in Figures 2010. Publications Office of the European Union, Luxembourg

De Ceuster G, van Herbrugger B, Logghe S, Proost S, Leuven K (2004). TREMOVE 2.2 model and baseline description. Final Report, European Commission. http://www.tremove.org

Dijkema MBA, van der Zee SC, Brunekreef B, van Strien RT (2008) Air quality effects of an urban highway speed limit reduction. Atmos Environ 42(40):9098-9105. doi:10.1016/j.atmosenv.2008.09.039

Fomunung I, Washington S, Guensler R, Bachman W (2001) Validation of the MEASURE automobile emissions model: a statistical analysis. Statistical Analysis and Modeling of Automotive Emissions 65

Gkatzoflias D, Kouridis C, Ntziachristos L, Samaras Z (2007) COPERT 4: COmputer Program to calculate Emissions from Road Transport User Manual (Version 5.0). European Environment Agency and Laboratory of Applied Thermodynamics. Thessaloniki, Greece. http:/www.emisia.com/docs/tech01.pdf

Hassel D, Weber F (1997) Estimation of pollutant emissions from transport: gradient influence on emission and consumption behaviour of light and heavy duty vehicles. Methodologies for Estimating Air Pollutant Emission from Transport: MEET, COST 319 final report

Hernandez S, Monzon A, Sobrino N (2013). Decarbonization of toll plazas: impact assessment of toll collection system management. Transport Research Board 2013 Annual Meeting, Washington D.C. 132687

Hickman J, Hassel D, Jourmard R, Samaras Z, Sorenson S (1999) Methodology for calculating transport emissions and energy consumption. Transport Research Laboratory. United Kingdom. http://www.inrets. fr/ur/lte/cost319/M22.pdf

Ison S, Wall S (2003) Market-and-non-market-based approaches to traffic-related pollution: the perception of key stakeholders. Int J Transp Manag 1(3):133-143. doi:10.1016/S1471-4051(03)00003-X

Kitthamkesorn S, Chen A, Xu X, Ryu S (2013) Modeling mode and route similarities in network equilibrium problem with go-green modes. Netw Spat Econ. doi:10.1007/s11067-013-9201-y

Koorey G (2009) Road data aggregation and sectioning considerations for crash analysis. Transp Res Rec: J Transp Res Board 2103(08):61-68

Lapillonne B, Sebi C, Pollier K (2012) Energy Efficiency Trends in the Transport Sector in the EU, Lessons from the ODYSSEE MURE project. http://www.odyssee-indicators.org/publications/PDF/transportenergy-efficiency-trends.pdf

Lenzen M (1999) Total requirements of energy and greenhouse gases for Australian transport. Transp Res Part D: Transp Environ 4(4):265-290. doi:10.1016/S1361-9209(99)00009-7

Li ZC, Wang YD, Lam WHK, Sumalee A, Choi K (2013) Design of sustainable cordon toll pricing schemes in a monocentric city. Netw Spat Econ. doi:10.1007/s11067-013-9209-3

Logghe S, Van Herbruggen B, Van Zeebroeck B (2006) Emissions of road traffic in Belgium. FEBIAC, FDT Mobility and Transport, Transport and Mobility Leuven, Belgium. https:/www.mobilit.fgov.be/data/ mobil/emrotra.pdf

Lopez E, Monzon A, Pfaffenbichler PC (2012) Assessment of energy efficiency and sustainability scenarios in the transport system. Eur Transp Res Rev 4(1):47-56

Lumbreras J, Guijarro A, Lopez J, Rodriguez E (2009) Methodology to quantify the effects of policies and measures in emission reductions from road transport. Urban Transport XV: Urban Transport and Environment, Bologna

Mendiluce M, Schipper L (2011) Trends in passenger transport and freight energy use in Spain. Energy Pol 39(10):6466-6475. doi:10.1016/j.enpol.2011.07.048

Mensik C, De Vlieger I, Nys J (2000) An urban transport emission model for the Antwerp area. Atmos Environ 34(27):4595-4602. doi:10.1016/S1352-2310(00)00215-6

MF (2010) Spanish Traffic Map 2009, Direccion General de Carreteras. Ministerio de Fomento MF, Madrid

Monzon A, Sobrino N, Hernandez S (2012) Energy- and Environmentally Efficient Road Management: The Case of the Spanish Motorway Network. Procedia - Soc Biol Sci 48:287-296

Namdeo A, Mitchell G, Dixon R (2002) TEMMS: An integrated package for modeling and mapping urban traffic emissions and air quality. Environ Model Softw 17(2):177-188

Nökel K, Schmidt M (2002) Parallel DYNEMO: Meso-scopic traffic flow simulation on large networks. Netw Spat Econ 2(4):387-403. doi:10.1023/A:1020851612407

Ntziachristos L, Mellios G, Kouridis C, Papageorgiou T, Theodosopoulou M, Samaras Z, Zierock K, Kouvaritakis N, Panos E, Karkatsoulis P, Schilling S, Merétei T, Bodor P, Damjanovic S, Petit A 
(2008) European Database of Vehicle Stock for the Calculation and Forecast of Pollutant and Greenhouse Gases Emissions with TREMOVE and COPERT: Final Report. Laboratory of Applied Thermodinamics, Thessaloniki, Greece. http://www.emisia.com/docs/08.RE.0009.V2\%20-\%20Fleets_Final.pdf

OECD, ITF (2010) Reducing transport greenhouse gas emissions: Trends and data 2010. Paris. http://www. internationaltransportforum.org/Pub/pdf/10GHGCountry.pdf. Accessed August 2012

Pandey D, Agrawal M, Pandey JS (2011) Carbon footprint: current methods of estimation. Environ Monit Assess 178(1-4):135-160. doi:10.1007/s10661-010-1678-y

Panis LI, Beckx C, Broekx S, De Vlieger I, Schrooten L, Degraeuwe B, Pelkmans L (2011) PM, NOx and $\mathrm{CO} 2$ emission reductions from speed management policies in Europe. Transp Policy 18(1):32-37. doi:10. 1016/j.tranpol.2010.05.005

Park S, Rakha H (2006) Energy and environmental impacts of roadway grades. Transp Res Rec: J Transp Res Board 1987(1):148-160

Pierson W, Gertler A, Robinson N, Sagebiel J, Zielinska B, Bishop G, Stedman D, Zweidinger R, Ray W (1996) Real-world automotive emissions - Summary of studies in the Fort McHenry and Tuscarora Mountain Tunnels. Atmos Environ 30(12):2233-2256

Saija S, Romano D (2002) A methodology for the estimation of road transport air emissions in urban areas of Italy. Atmos Environ 36(34):5377-5383

Shuangjian J, Chengcheng H, Yanwei L, Qunle D (2011) Establishing the CO2 emission model of carbon neutral road based on gradient. 2011 International Conference on Electrical and Control Engineering, ICECE 2011 -Proceedings, 4494-4497

Silva CM, Farias TL, Frey HC, Rouphail NM (2006) Evaluation of numerical models for simulation of realworld hot-stabilized fuel consumption and emissions of gasoline light-duty vehicles. Transp Res Part D: Transp Environ 11(5):377-385. doi:10.1016/j.trd.2006.07.004

Smit R, Smokers R, Rabe E (2007) A new modeling approach for road traffic emissions: VERSIT. Transp Res Part D-Transp and Environ 12(6):414-422

Smit R, Poelman M, Schrijver J (2008) Improved road traffic emission inventories by adding mean speed distributions. Atmos Environ 42(5):916-926. doi:10.1016/j.atmosenv.2007.10.026

Smit R, Ntziachristos L, Boulter P (2010) Validation of road vehicle and traffic emission models - A review and meta-analysis. Atmos Environ 44(25):2943-2953. doi:10.1016/j.atmosenv.2010.05.022

Sobrino N, Monzon A (2013) Management of urban mobility to control climate change in cities. Transportation Research Record: Journal of the Transportation Research Board. Transport Research Board 2013 Annual Meeting, Washington D.C. 13-1470

Szeto WY, Jaber X, Wong SC (2013a) Road network equilibrium approaches to environmental sustainability. Transp Rev 32(4):491-518. doi:10.1080/01441647.2012.690000

Szeto WY, Jiang Y, Wang DZW, Sumalee A (2013b) A sustainable road network design problem with land use transportation interaction over time. Netw Spat Econ. doi:10.1007/s11067-013-9191-9

Taylor NB (2003) The CONTRAM dynamic traffic assignment model. Netw Spat Econ 3(3):297-322. doi:10. 1023/A:1025394201651

Tsang KS, Hung WT, Cheung CS (2011) Emissions and fuel consumption of a Euro 4 car operating along different routes in Hong Kong. Transp Res Part D-Transp Environ 16(5):415-422. doi:10.1016/j.trd.2011. 02.004

U.S.EPA (2002) MOBILE6 Vehicle Emission Modeling Software, EPA-420-R-02-001, United States Environmental Protection Agency, http://www.epa.gov/otaq $/ \mathrm{m} 6 . \mathrm{htm}$. Accessed May 2013

U.S.EPA (2009) MOVES2010a Mobile Source Emissions Model Update, EPA-420-B-09-041, United States Environmental Protection Agency, http://www.epa.gov/otaq/models/moves/420b09041.pdf. Accessed May 2013

UNFCC (1998) Kyoto Protocol to the United Nations Framework Convention on Climate Change

Valackiene A, Miceviciene D, Sandbaek M (2006) Development of transport infrastructure: dimensional analysis of economic effects. In Changes in Social and Business Environment: Proceedings of the 1st International Conference: $210-213$

Wackemagel M, Rees WE (1996) Our ecological footprint: reducing human impact on the earth. New Society Publishers, Canada 